\title{
COL12A1 Single Nucleotide Polymorphisms rs240736 and rs970547 Are Not Associated with Temporomandibular Joint Disc Displacement without Reduction
}

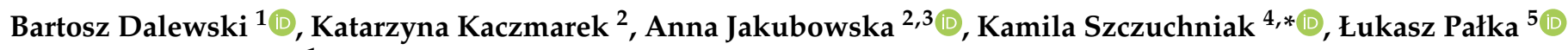 \\ and Ewa Sobolewska ${ }^{1}$ \\ 1 Department of Dental Prosthetics, Pomeranian Medical University, 70-111 Szczecin, Poland; \\ bartosz.dalewski@pum.edu.pl (B.D.); rpsobolewski@wp.pl (E.S.) \\ 2 Department of Genetics and Pathology, Pomeranian Medical University, 71-252 Szczecin, Poland; \\ katarzyna.kaczm@gmail.com (K.K.); aniaj@pum.edu.pl (A.J.) \\ 3 Independent Laboratory of Molecular Biology and Genetic Diagnostics, Pomeranian Medical University, \\ 71-252 Szczecin, Poland \\ 4 Department of Dental Prosthetics, Outpatient Dental Clinic, Pomeranian Medical University, \\ 70-111 Szczecin, Poland \\ 5 Private Dental Practice, 68-200 Żary, Poland; dr.lpalka@gmail.com \\ * Correspondence: kamila.szczuchniak@gmail.com
}

Citation: Dalewski, B.; Kaczmarek, K.; Jakubowska, A.; Szczuchniak, K.; Pałka, Ł.; Sobolewska, E. COL12A1 Single Nucleotide Polymorphisms rs240736 and rs970547 Are Not

Associated with Temporomandibular Joint Disc Displacement without Reduction. Genes 2021, 12, 690. https: / / doi.org/10.3390/ genes12050690

Academic Editors: Emiliano Giardina and Albert Jeltsch

Received: 21 February 2021

Accepted: 1 May 2021

Published: 5 May 2021

Publisher's Note: MDPI stays neutral with regard to jurisdictional claims in published maps and institutional affiliations.

Copyright: (c) 2021 by the authors. Licensee MDPI, Basel, Switzerland. This article is an open access article distributed under the terms and conditions of the Creative Commons Attribution (CC BY) license (https:// creativecommons.org/licenses/by/ $4.0 /)$.

\begin{abstract}
Temporomandibular disorders (TMDs) may affect up to $25 \%$ of the population, with almost $70 \%$ of these TMD cases developing malpositioning of the disc over time in what is known as internal derangement (ID). Despite significant efforts, the molecular mechanism underlying disease progression is not yet very well known. In this study, the role of COL12A1 rs970547 and rs240736 polymorphisms as potential genetic factors regulating ID was investigated. The study included 124 Caucasian patients of both sexes after disc displacement without reduction (DDwoR) in either one or two temporomandibular joints (TMJs), either of which meet the criteria for this condition. All patients underwent clinical examination and 3D digital imaging. The COL12A1 rs970547 and rs240736 polymorphisms were evaluated. There were no statistically significant differences in the chi-square test between the study group and healthy controls. The examined COL12A1 rs240736 and rs970547 polymorphisms do not contribute to DDwoR in Polish Caucasians.
\end{abstract}

Keywords: TMJ; DDwoR; polymorphism; SNP; articular disc; TMD; disc displacement; COL12A1; rs970547; rs240736

\section{Introduction}

The temporomandibular joint (TMJ) is a complex, bilateral structure that allows the mandible to move in three different directions. It consists of the articular surfaces of the temporal bone, the mandibular condyle, articular fibrocartilaginous disc, joint capsule, and ligaments. Articular surfaces of the condyle and the mandibular fossa are covered with fibrous (noncellular, nonvascular) cartilage, surrounded by synovial fluid, which ensures smooth and unaffected mandible movement correlated with teeth morphology throughout the chewing cycle. A fibrous capsule, covered externally by the periosteum, connects both joint surfaces and closes the synovial fluid within the joint cavity. The articular disc in the TMJ plays an inessential role in jaw kinematics and comprises the fibrocartilage, while the extracellular matrix (ECM) of this disc mostly comprises a collagenous network of mainly collagen type I and III, elastin fibers, glycosaminoglycans (GAGs), and proteoglycans [1]. So far, the expression of type I and III collagen markers in human fetal TMJ discs using immunohistochemical (IMHC) methods was confirmed [2], as they showed type I collagen presence in the posterior band of the articular disc, but type III collagen on the lower surface of the articular disc. Connective tissues exhibit heterogeneous, anisotropic, and hyperelastic 
activity in response to jaw movement and various occlusal loading, with collagen tissues limiting tissue expansion [3]. The ligaments in the human temporomandibular joint are partially elastic and restrict three-dimensional movement to some extent, while retrodiscal tissues play a major role in proprioception, providing sensory information about the jaw position and the force exerted by the masticatory muscles. That unique developmental composition makes the TMJ more resilient to degenerative changes over time than hyaline cartilage in other synovial joints [4]. Nevertheless, it is estimated that temporomandibular disorders (TMDs) may affect up to $25 \%$ of the population, and almost $70 \%$ of these TMD cases will develop misplacement/dystopia of the disc over time, which is called internal derangement (ID). Despite significant efforts, the molecular mechanism underlying disease progression is not yet very well known. It seems that ID strongly correlates with TMJ osteoarthritis (OA) as a symptom or a contributing factor in a later stage of TMD, affecting mostly older patients. It may occur in people of all ages, but a higher incidence was found in women in their 20s [5]. The most common types of TMJ ID are anterior or antero-mesial disc displacement (DD) with (DDwR) or without reduction (DDwoR) [6]. In DDwoR, the disc moves forwards and usually also slightly medially to the lower rest position, where it remains locked and painful upon mouth opening, as most MRI studies brought up in recent years [7-9]. The need for thorough evaluation and multi-section analysis in both TMJ sagittal and coronal planes has also been described [10]. The etiology is not yet fully explained, but there are a few possible reasons causing IDs of TMJ structures. According to most data, bruxism, anatomical factors, history of trauma, or generalized joint hypermobility (GJH) are considered major contributing factors [11]. A displaced TMJ disc can be reduced at an earlier stage; it is likely to transform into a non-reducing form over a few weeks. As it happens, the TMJ disc does not return to its physiological position, but becomes displaced and may prevent appropriate movement of the condyle, causing pain in the preauricular area and limitation within the mandible range of motion, affecting daily activities, as shown in Figures 1-3.

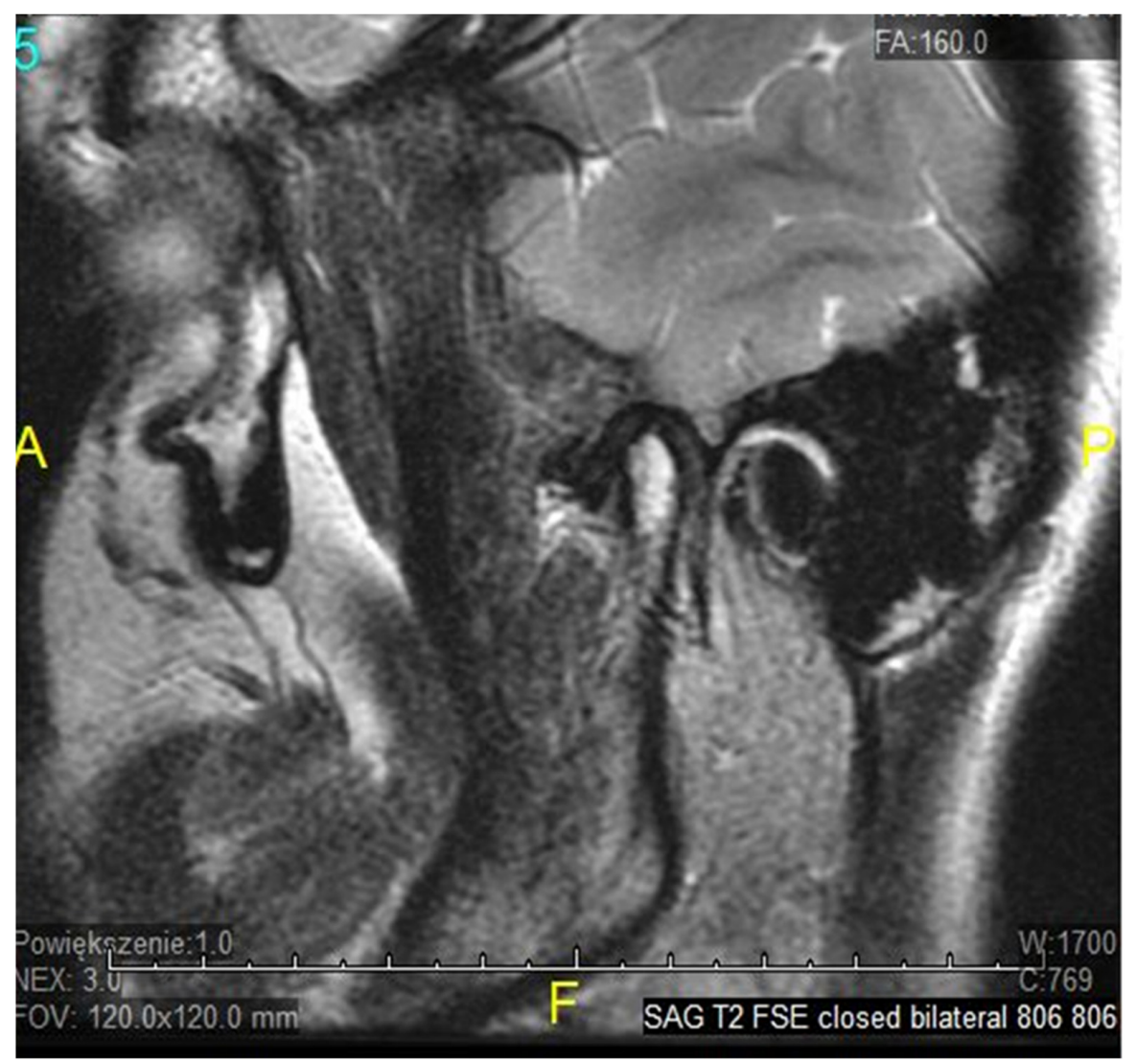

Figure 1. ADDwoR sagittal view—closed. 


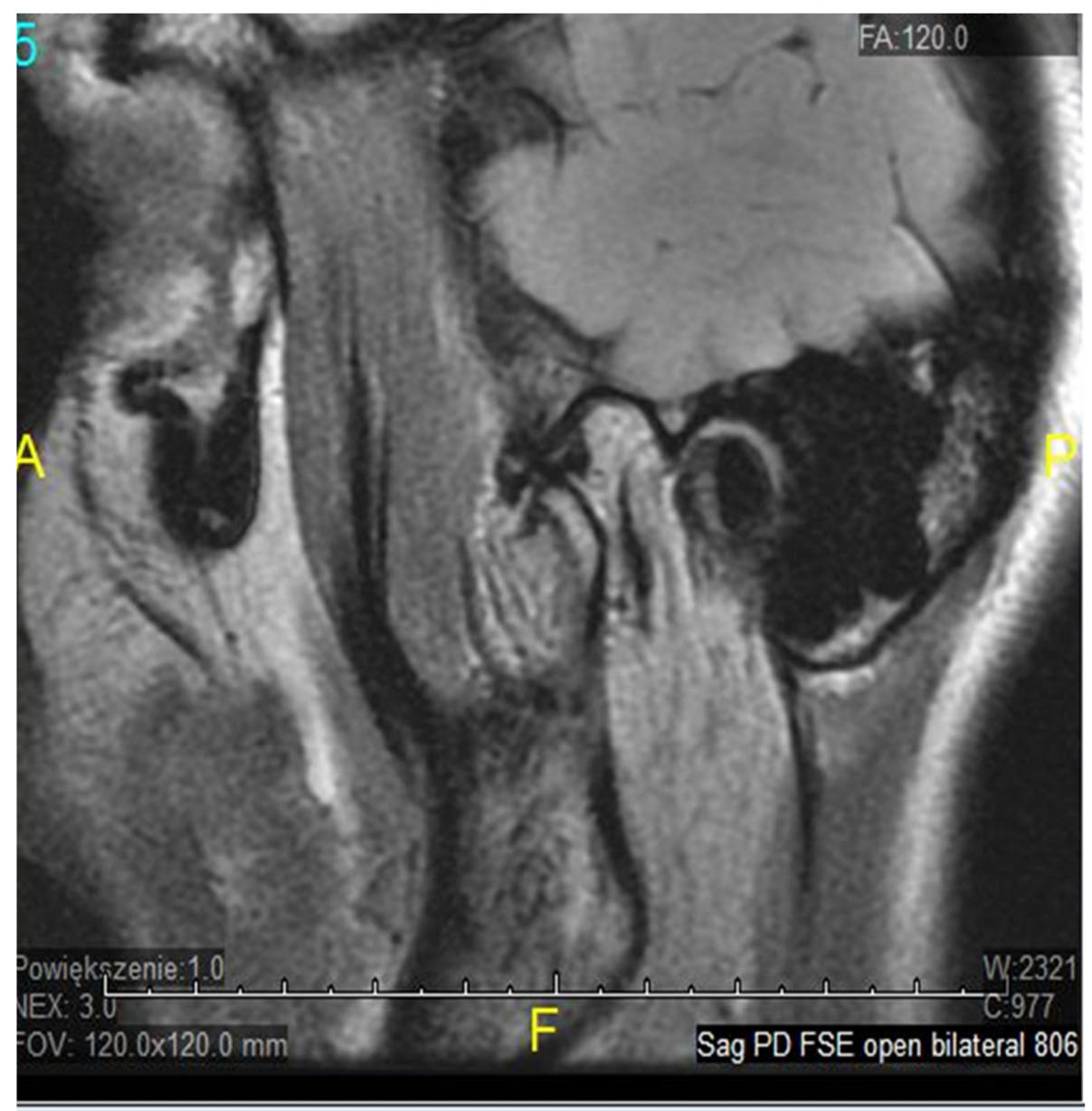

Figure 2. ADDwoR sagittal view—open.

Magnetic Resonance Imaging (MRI) scans showed that in cases where no treatment has been administered, the displaced TMJ disc becomes deformed [12]. It was also found that unilateral DDwoR in young people can lead to asymmetry of the mandible over time [13]. Moreover, it has been proven that the severity of asymmetry increases with time and may require orthognathic surgery later in life [14]. The TMJ disc is connected in its dorsal part with an area of richly innervated and vascularized connective tissue. This tissue is defined as the bilaminar zone (BLZ). The lower layer is mainly composed of collagen fibers. In addition, the front part of the disc is connected from the top and bottom by trailers to the joint capsule. Both front trailers are made of collagen blocks [15]. Collagen XII is a fiber-bound, single gene encoded by COL12A1, a member of the fibrilassociated collagens with interrupted triple helices collagens (FACIT) located on human chromosome 6q12-q13. By providing unique molecular bridges between fibrils and other ECM components, the FACIT collagens tend to act as regulators of fibrillar scaffolds (Figure 1). Some partial correlation between COL12A1 Single Nucleotide Polymorphisms (SNPs) [16] and joint disorders was previously reported; however, just one of the studies brought up the relationship between rs970547 in COL12A1 with anterior cruciate ligament (ACL) rupture [17]. Nevertheless, more research on this subject is required in terms of other parts of the musculoskeletal system [1-4]. Furthermore, a connection between mutations in COL12A1 and Ehlers-Danlos Syndrome (EDS) has also been demonstrated [18]; whereas a major part of EDS symptomatology is strictly connected with GJH and hyper elastic skin, TMJ posterior band ligaments, which are primarily composed of collagen fibers defined by a certain length, have also been shown to play a significant role in preventing TMJ disc displacement [19]. We hypothesized that some IDs in the TMJ might be caused by impaired collagen quality and certain COL12A1 SNPs, yet a relationship to TMJ internal 
derangements might be assumed. There were some previous data published related to COL12A1 [18] and COL2A1 [20], however no variants of these genes in terms of DDwoR were assessed. In this study, we chose to investigate the role of COL12A1 rs970547 and rs240736 polymorphisms as potential factors influencing genetic variability of DDwoR in Polish Caucasians. Figure 4 presents possible gene-gene interactions related to COL12A1 according to the STRING database [21].

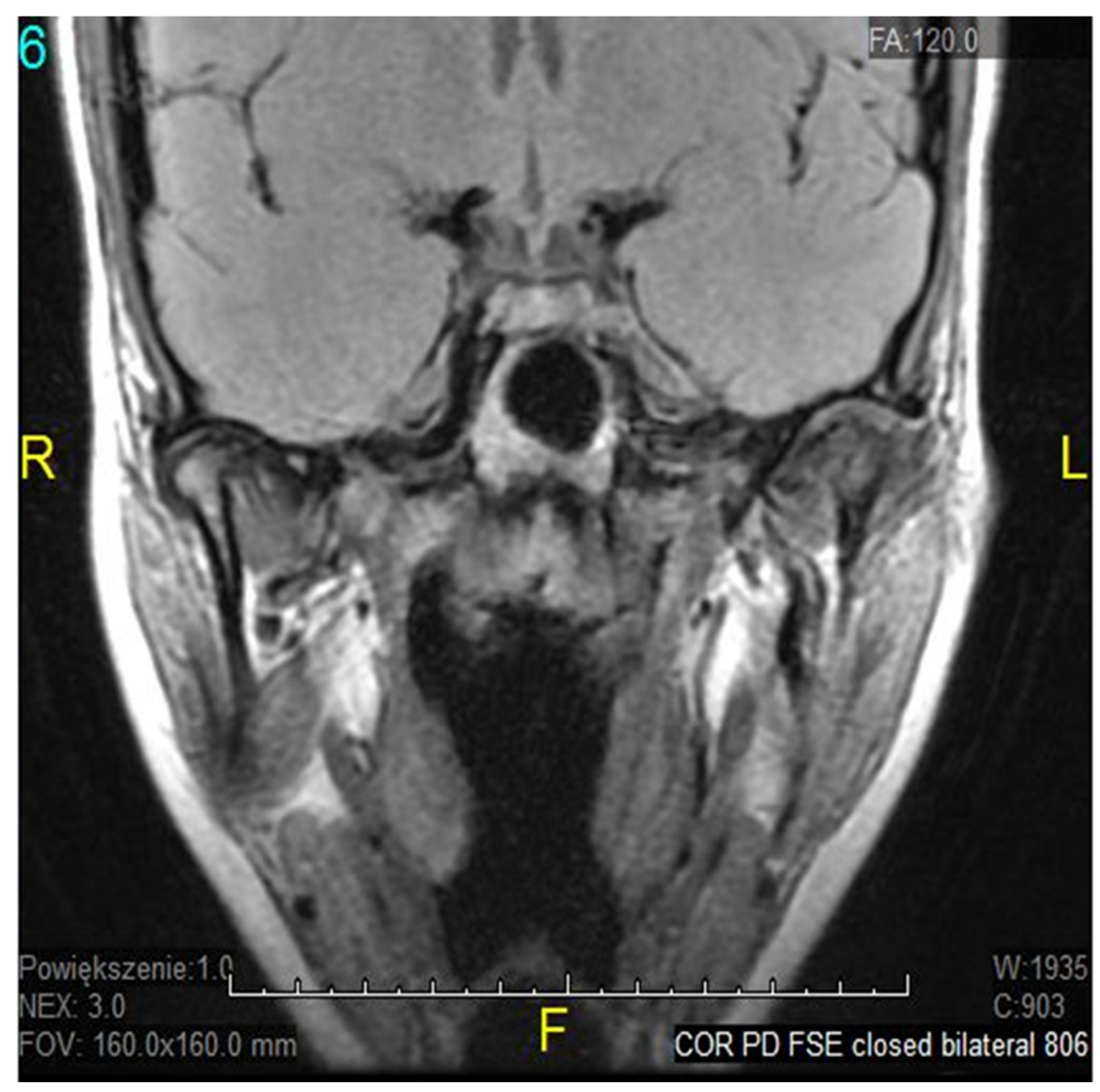

Figure 3. ADDwoR coronal view-closed. 


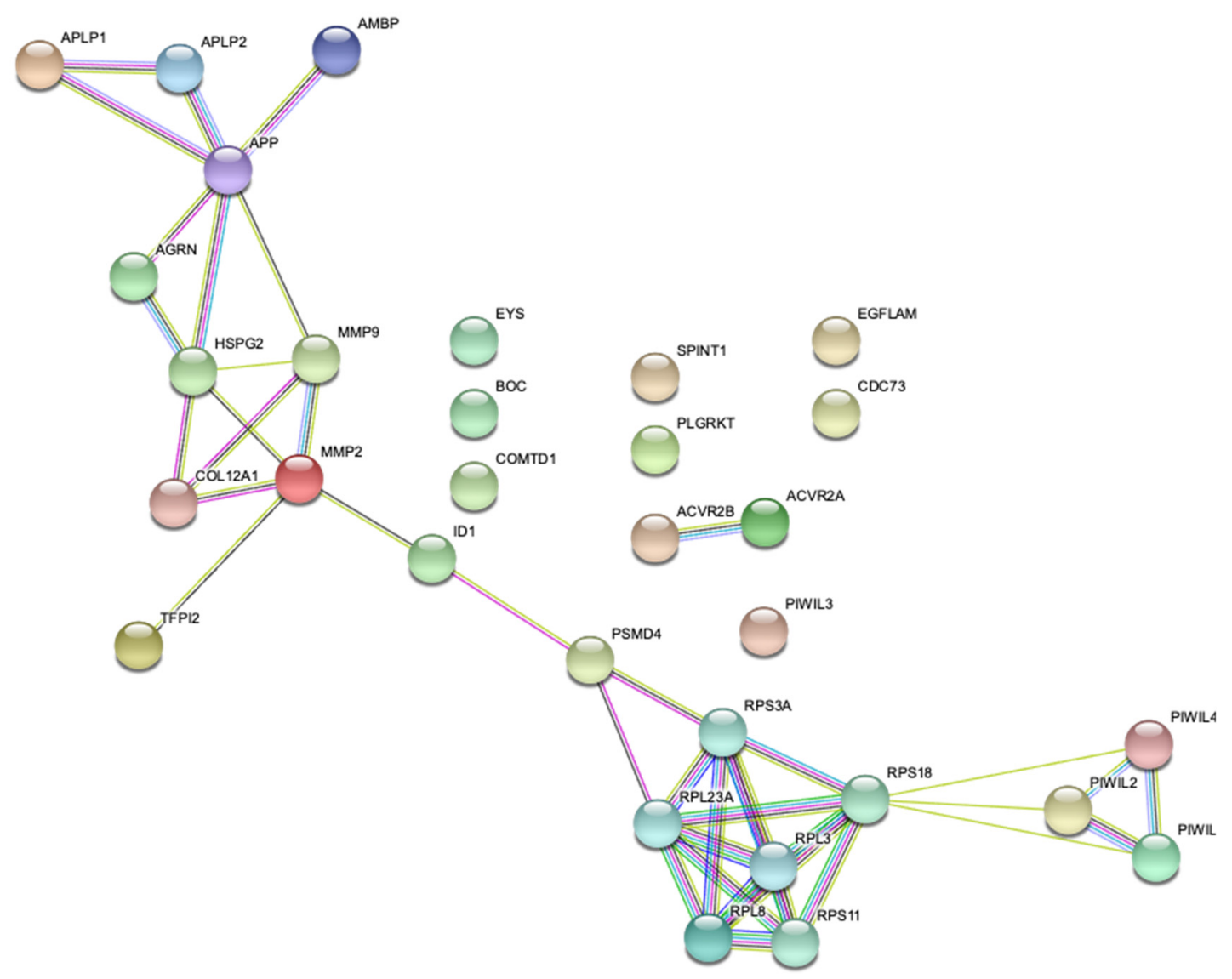

Figure 4. COL12A1 possible gene-gene interactions.

\section{Materials and Methods}

In this case-control study, the examined group was recruited from among patients who sought TMD treatment between 2014 and 2018 and presented to the Department of Dental Prosthetics at the Pomeranian Medical University in Szczecin, Poland. It consisted of 124 Caucasian patients, unrelated, of both sexes. Each patient had an episode of DDwoR no more than 3 months prior and signed an informed consent form before study registration. DDwoR was diagnosed according to clinical examination, diagnostic criteria of the temporomandibular disorder questionnaire (DC/TMD), and CBCT/MRI scan [22-25]. The control group comprised 126 patients with no TMD problems according to DC/TMD-they were selected from the rest of the patients treated at the outpatient dental clinic. Additional exclusion criteria for both groups were as follows: pathological tooth mobility (grade 1 or more on the Hall scale), previous experience with occlusal splint therapy, not all areas of occlusal support present, coexisting pathology or inflammation within the jaws or head and neck muscles, accompanying metabolic diseases or identified connective tissue defects.

\subsection{SNPs Selection}

In this study, we considered the genetic role of the COL12A1 gene rs970547 and rs240736 expression as a potential cause of DDwoR expression.

DNA isolation: Genomic DNA was isolated from buccal epithelial cells using SWAB Genomic Extraction GPB Mini Kit (Genoplast Biochemical, Gdansk, Poland) in compliance with the producer's manual.

\subsection{Molecular Analyses}

Genotyping of COL12A1 SNPs rs970547 and rs240736 was performed by real-time PCR using TaqMan probes and analyzed using pre-designed Applied Biosystems TaqMan real-time PCR assays (Applied Biosystems, Foster City, CA, USA). 
The reaction mix for each sample contained GoTaq ${ }^{\circledR}$ Probe qPCR Master Mix (Promega, Madison, WI, USA), TaqMan real-time PCR assays (Applied Biosystems, Foster City, CA, USA), and nuclease-free, deionized water, strictly adhering to the manufacturer's protocol.

The reaction mix, DNA, and no-template control (NTC) were pipetted into 384-well plates (Axygen Inc., Union City, CA, USA). Real-time PCR was performed on LightCycler ${ }^{\circledR}$ 480 (Real-Time PCR System, Roche Diagnostics, Basel, Switzerland). Genotyping data were analyzed using LightCycler480 Basic Software (Version 1.5, Roche Diagnostics, Basel, Switzerland).

\subsection{Statistical Analysis}

Further on in the analysis, COL12A1 rs970547 and rs240736 odds were calculated in respect to the most frequent combination, with respective confidence intervals of $95 \%$. The significance of differences in the distribution of genotypes was analyzed using Pearson's chi-square test. Logistic regression modeling was performed to analyze the association of selected SNPs with DDwoR. Data are presented as allele frequencies and odds ratio (OR) with $95 \%$ confidence interval (CI). The Mann-Whitney U test was performed to determine the age difference between the groups. $p<0.05$ was considered to be statistically significant. Calculations were completed with MATLAB R2018b (MathWorks, Natick, MA, US, 2018).

\section{Results}

Patient Characteristics, Odds Ratio, and Logistic Regression Analysis

The studied and acquired data were first analyzed using descriptive statistics in relation to groups. Additionally, a chi-square test was performed in order to check for independence. Table 1 describe the results of the preliminary analysis.

Table 1. Patient characteristics by group.

\begin{tabular}{|c|c|c|c|c|c|c|c|c|}
\hline & & \multicolumn{2}{|c|}{$\begin{array}{c}\text { Total } \\
n=250\end{array}$} & \multicolumn{2}{|c|}{$\begin{array}{c}\text { Case } \\
n=124\end{array}$} & \multicolumn{2}{|c|}{$\begin{array}{l}\text { Control } \\
n=126\end{array}$} & \multirow[t]{2}{*}{$p$-Value * } \\
\hline & & $\mathbf{N}$ & $\%$ & $\mathbf{N}$ & $\%$ & $\mathbf{N}$ & $\%$ & \\
\hline \multirow[b]{2}{*}{ Sex } & $\mathrm{F}$ & 200 & 80.00 & 104 & 83.87 & 96 & 76.19 & \multirow[b]{2}{*}{0.129} \\
\hline & M & 50 & 20.00 & 20 & 16.13 & 30 & 23.81 & \\
\hline \multirow{4}{*}{ Age } & $<24$ & 54 & 21.60 & 40 & 74.07 & 14 & 25.93 & \multirow{4}{*}{$<0.01$} \\
\hline & $24-33$ & 70 & 28.00 & 37 & 52.86 & 33 & 47.14 & \\
\hline & $34-50$ & 65 & 26.00 & 33 & 50.77 & 32 & 49.23 & \\
\hline & $\geq 50$ & 61 & 24.40 & 14 & 22.95 & 47 & 77.05 & \\
\hline \multirow[t]{2}{*}{ Age } & & \multicolumn{2}{|c|}{ Total } & \multicolumn{2}{|c|}{ Case } & \multirow{2}{*}{\multicolumn{2}{|c|}{$\begin{array}{c}\text { Control } \\
39(28-60)\end{array}$}} & \multirow{2}{*}{$\begin{array}{c}p \\
<0.01\end{array}$} \\
\hline & Median (Q1-Q3) & & & & 39) & & & \\
\hline
\end{tabular}

There is no significance in the $p$-value of the test when comparing men and women in this case-control study. The age of the case group was significantly lower than controls.

In further analyzing the polymorphisms, the odds were calculated in respect to the most frequent combination, with respective confidence intervals of $95 \%$. A chi-squared test at 0.05 confidence level was performed in order to check for the association. The results of the odds ratio analysis are shown in Table 2. In this study, COL12A1 markers rs970547 and rs240736 had no significant $p$-values (chi-squared), implying that there is no difference in terms of TMJ DDwoR frequency. 
Table 2. Odds ratio analysis.

\begin{tabular}{|c|c|c|c|c|c|c|c|}
\hline & & Case & Control & OR & \multicolumn{2}{|c|}{$95 \% \mathrm{CI}$} & $p$-Value * \\
\hline \multicolumn{8}{|c|}{ COL12A1 rs970547 } \\
\hline \multirow[t]{3}{*}{ Reference } & $\mathrm{TT}$ & 75 & 76 & 1 & & & \multirow{3}{*}{$0.71^{* *}$} \\
\hline & $\mathrm{CC}$ & 4 & 2 & 0.4934 & 0.0877 & 2.77 & \\
\hline & $\mathrm{CT}$ & 45 & 46 & 1.0088 & 0.5996 & 1.6972 & \\
\hline \multicolumn{8}{|c|}{ COL12A1 rs240736 } \\
\hline \multirow[t]{3}{*}{ Reference } & $\mathrm{AA}$ & 72 & 68 & 1 & & & \multirow{3}{*}{$0.157^{* *}$} \\
\hline & AG & 36 & 47 & 1.3824 & 0.8006 & 2.3868 & \\
\hline & GG & 15 & 8 & 0.5647 & 0.2251 & 1.4168 & \\
\hline
\end{tabular}

A multivariable logistic regression model was applied as well, but no significant model was found in the study in the case of rs970547 and rs240736. The lack of significance in the chi-square statistic vs. constant model test is shown in Table 3.

Table 3. Multivariable, sex, and age-adjusted logistic regression modeling for COL12A1 SNPs rs970547 and rs240736.

\begin{tabular}{ccccccc}
\hline & & aOR & \multicolumn{2}{c}{$\mathbf{9 5 \%}$ CI } & $p$-Value & Power \\
\hline Sex & m & 0.61 & 0.31 & 1.21 & 0.16 & 0.93 \\
\hline \multirow{2}{*}{ rs970547 } & TT & 1.03 & 0.59 & 1.82 & 0.91 & 0.7 \\
& CC & 1.97 & 0.32 & 12.25 & 0.47 & 0.99 \\
\hline \multirow{2}{*}{ rs240736 } & GG & 2.40 & 0.86 & 6.75 & 0.10 & 0.98 \\
Age & AG & 0.74 & 0.41 & 1.33 & 0.31 & 0.90 \\
& & 0.96 & 0.94 & 0.97 & $<0.01$ & 0.99 \\
\hline
\end{tabular}

The results shown in Tables 2 and 3 indicate that both COL12A1 markers rs240736 and rs970547 are not associated with the odds of TMJ DDwoR.

\section{Discussion}

This is the first study of its type defining the relationship between COL12A1 markers rs 970547 and rs240736 in TMJ DDwoR. It is a part of a larger project about molecular underlying conditions influencing this issue-whereas ESR1 rs1643821 is positively associated so far [26]. The main finding of our present investigation is that COL12A1 markers rs240736 and rs970547 were not significant for TMJ DDwoR; therefore within our sample size, these SNPs do not contribute to the risk of articular disc displacement (ADDwR).

Differences in protein expression comparing core matrisome of 9 fetal and 7 healthy adult nucleus pulposus (NP) were previously identified with the use of proteomic and bioinformatic methods; however, collagen 12a1 protein was upregulated in the fetal NPs involved in ECM assembly pathways. By contrast, even though concentrations were low and mostly limited in the degenerated state, proteins that were usually absent in adult discs were re-expressed, with one of them showing substantially increased expression relative to stable adult discs [27]. It may suggest the involvement of collagen XII in degenerated state pathways, for instance, by acting as an inhibitor or regulator in regenerative processes. As a compensatory mechanism, these proteins may be upregulated [28]. Interestingly, mature collagen 12a1 and 14a1 are not found in the main fibrillar structure; however, the 12a1 form is thought to be involved in tail and spinal cord regeneration in certain species. It is also plays a role in the regulation and organization of collagen fibril bundles, hydration, and thickness.

Nevertheless, compelling data regarding these three types of collagen are limited and more research on their role in intervertebral disc degeneration and regenerative pathways is required [29]. Specific COL12A1 genotypes were also previously linked to Bethlem 
myopathy (BM). This slowly progressing muscle disease is characterized by proximal weakness, muscle contractures, the rigidity of the spine, and skin abnormalities. One of the well-known genetic causes of $\mathrm{BM}$ is a dominant, or, less frequently, a recessive mutation in one of the collagen VI genes (COL6A1, COL6A2, and COL6A3). Hicks et al., in their studies involving $24 \mathrm{BM}$-like patients, identified novel causal variants, sequencing other genes [30]. They hypothesized that these variants may be responsible for the non-collagen VI overlapping BM phenotype in COL12A1 in 2 families, leading to the conclusion that the disease might also be inherited in an autosomal dominant way. Similarly, Punetha et al. described dominant missense mutations in the COL12A1 gene in mild Bethlem-like myopathy in 6 patients from 3 families. Their model patient, an 8-year old Polish girl, experienced profound hypotonia and joint hyperlaxity. They used a targeted sequencing panel to identify a potentially novel, pathogenic heterozygous missense COL12A1 c.8329G >C (p.Gly2777Arg) variant. In addition, studies on fibroblasts revealed that the COL12a1 protein was retained intracellularly, indicating a dominant-negative mutation. They concluded that COL12A1 disorders seem to additionally cover a considerable part of an Ehlers-Danlos/Bethlem-like myopathy severity, and collagen XII-related conditions should become a part of a detailed examination while diagnosing patients with an overlapping phenotype that is associated with both muscle and connective tissue inherited defects [31].

Ligaments, capsules, and tendons insert into the underlying bone in a specific anatomical zone called the enthesis, a multilayered structure transmitting mechanical stress caused by movement from the tendons or ligaments onto the underlying bone. Despite the uncalcified fibrocartilage layer through which the collagen fibers of tendon or ligaments are passing, it is followed by a calcified fibrocartilage string, which subsequently inserts onto the hard tissue [32]. The irregular transition between fibrocartilage and the underlying bone increases the bond surface and adds tensile strength [33]. In chronic joint disorders, such as rotator cuff pathology, this synovio-entheseal complex is thought to play a crucial role. Type II collagen showed promising results in the Harada et al. study, indicating that rotator-cuff-derived cell sheet could facilitate cartilage regeneration and angiogenesis at the enthesis, while having superior mechanical strength to that found in the control group. However, they speculated that in the case of a rotator cuff injury, collagen-rich cell sheets might be a successful regenerative strategy for both enthesis and tendon in potential tissue engineering techniques [34]. ACL injuries were also previously associated with COL12A1 in a Chinese population-rs970547 and rs240736 had a correlation with ACL injury frequency in Chinese men. Males with COL12A1 rs970547A allelic gene and AA genotype were found to be more susceptible to ACL injury [35].

Collagen XII mutations have recently been linked with changes in connective tissue, with phenotypic manifestations similar to collagen VI-related myopathies. Araújo and Antunes reported a novel mutation identified in a 14-year old Caucasian girl suffering from persistent clavicle dislocation, GJH, and a small decrease of the strength of the upper limbs. Once mutations in collagen VI have been ruled out, a heterozygous missense mutation in COL12A1-c.8336G > A- indicates a potential link to collagen XII-related disorders in individuals with an overlapping phenotype with muscle and connective tissue defects combined [36]. Another study showed that COL12A1 rs970547 should not be associated with the analyzed range of motion. The interaction effects between age and genotype found in the variants and range of motion measurements among studied groups were also not significant [37].

This finding is partially consistent with our research, as the COL12A1 rs970547 group did not correlate with symptoms and their occurrence. A similar association of COL12A with GJH phenotypes and their phenotypic variability was emphasized and described by Jezela-Stanek et al. [38]. The COL12A1 was associated with ACL ruptures among female participants in the study by Posthumus et al. Despite the fact that the AA genotype of the COL12A1 AluI RFLP was substantially over-represented in female ACL patients, but not in male, it was concluded that these preliminary genetic association studies should be further investigated and, if replicated, integrated into screening models developed to 
identify genetically predisposed patients [39]. The COL12A1 A9285G polymorphism was also assessed by Ficek et al. in Polish male football players. While the frequency of the $G$ allele was lower in the cases, it was not statistically significant [40]. In a following study by Ficek et al., no association between the A9285G COL12A1 polymorphism and ACL ruptures was found in the group of male athletes [41]. Subsequently, $\mathrm{O}^{\prime} \mathrm{Connell} \mathrm{et} \mathrm{al.,} \mathrm{in} \mathrm{a}$ joint Polish-South African study performed on patients with surgically diagnosed ACL ruptures, scrutinized COL12A1 rs97054, among a few other collagen SNPs. They confirmed COL12A1 rs970547 (A/G) variants and the risk of ACL injury in females. Interestingly, COL12A1 rs970547 was not associated with the risk of ACL injury in a larger female South African cohort. What is more, the COL12A1 rs970547 AA genotype was significantly associated with a reduced risk of ACL ruptures in Polish female patients, consistently with earlier results [38]. These data collectively emphasize the need for investigating gene-gene interactions in the etiology of ACL ruptures and other joint-tendon pathology in multiple independent cohorts, including varying ethnicity [38-41]. Bell et al. raised the issue of different collagen genes and joint laxity, finding that the COL12A1 AA genotype improved anterior knee laxity in comparison to the AG + GG genotypes. These findings are plausible because the rs 970547 amino acid location (glycine to serine at position 3058 in the protein sequence; G3058S) is found within the NC1 functional binding domain [42], which is needed for collagen matrix organization. This NC1 domain protrudes from the main structure and serves as an interaction platform for ECMs and possibly other collagen fibers [43]. If this amino acid change alters the binding domain significantly, the altered collagen structure may be presented clinically through joint laxity and ultimately in ACL rupture [44].

The initial hypothesis of Novaretti et al. was that mRNA expression of ligament healing factors in the ACL would be higher in acute tears less than 3 months from injury than it would be in intermediate (3 to 12 months) and chronic (more than 12-month-old injuries). As it turned out, among the other genes studied, COL12A1 expression in the ACL remnant is greater in the acute phase of healing ( $<3$ months from injury) in comparison to chronic ( $>12$ months old) injuries [45]. In the formed tendon, cellular structure and fibril packing were essential determinants of its biomechanical properties. Collagen XII deficiency affected the structure, relationships, and intercellular collagen communication of tenocytes. Tenocyte interaction and organization were disrupted when regulatory domains were impaired. They concluded that patients with altered COL12A1 expression may be affected by abnormal tendon extracellular matrix composition, specifically fiber assembly [46].

\section{Conclusions}

The data gathered in this study suggest that there is no association between the COL12A1 rs970547, rs240736 and DDwoR in Polish Caucasians. However, the lack of statistical significance in genotype and allele distribution does not rule out the possibility that the investigated polymorphisms do influence DDwoR. Pathologies associated with ligaments, joints, and tendons are complex phenomena and may be caused by a variety of proteins expressed on different chromosomes (gene-gene interactions, as shown in Figure 4). It is also plausible that interactions between these genetic factors and a number of environmental aspects (gene-environment interactions) might be crucial. Our findings may contribute to the understanding of the genetic mechanism underlying DDwoR, but further experimental studies on COL12A1 polymorphisms, including their interaction with other genes, are needed to fully understand these processes. Furthermore, a larger sample of participants, perhaps from different ethnic backgrounds, is required to confirm our results.

Author Contributions: Conceptualization, B.D.; methodology, A.J. and K.K.; bioinformatics analysis, B.D.; validation, B.D., A.J., and K.K.; formal analysis, B.D., A.J., and K.K.; investigation, B.D.; resources, B.D. and K.K.; data curation, B.D.; writing-original draft preparation, B.D.; writingreview and editing, B.D., K.S., Ł.P.; supervision, A.J. and E.S.; project administration, B.D. and K.S.; 
funding acquisition, B.D. and E.S. All authors have read and agreed to the published version of the manuscript.

Funding: The research was supported by a grant from the Pomeranian Medical University in Szczecin (MB-274-120/14/2014).

Institutional Review Board Statement: The study was approved by the Ethics Committee of the Pomeranian Medical University in Szczecin, Poland according to Good Clinical Practice (resolution number KB-0012/88/14).

Informed Consent Statement: Study had been preceded by obtaining written formal consent from the patients who underwent thorough medical examination. They were enrolled into both groups by a trained, calibrated examiner prior to buccal swab collection.

Data Availability Statement: We would not like to disclose the data, as they are sensitive according to our agreement with patients enrolled.

Acknowledgments: The authors would like to thank the patients participating in the study for their cooperation and compliance and a nursery staff for invaluable help in carrying out the patients' examination. We would also like to express our gratitude to Bogumiła Fraczak, former Head and Chair of the Department of Dental Prosthetics, Pomeranian Medical University of Medical Sciences, for her great and indispensable support at the early stage of the project.

Conflicts of Interest: The authors declare no conflict of interest.

$\begin{array}{ll}\text { Abbreviations } \\ \text { ACL } & \text { anterior cruciate ligament } \\ \text { ADD } & \text { anterior disc displacement } \\ \text { DDwoR } & \text { disc displacement without reduction } \\ \text { DDwR } & \text { disc displacement with reduction } \\ \text { CBCT } & \text { cone beam computed tomography } \\ \text { cEDS } & \text { classical type of Ehlers-Danlos syndrome } \\ \text { CI } & \text { confidence interval } \\ \text { CL } & \text { confidence level } \\ \text { COL12A1 } & \text { collagen, Type XII, } \alpha 1 \\ \text { CTS } & \text { carpal tunnel syndrome } \\ \text { DC/TMD } & \text { diagnostic criteria of temporomandibular disorders } \\ \text { ICR } & \text { idiopathic condylar resorption } \\ \text { MRI } & \text { magnetic resonance imaging } \\ \text { n } & \text { sample size } \\ \text { NT } & \text { no template control } \\ \text { OI } & \text { osteogenesis imperfecta } \\ \text { OR } & \text { odds ratio } \\ p \text {-value } & \text { level of probability } \\ \text { PCR } & \text { polymerase chain reaction } \\ \text { SNP } & \text { single nucleotide polymorphism } \\ \text { TMD } & \text { temporomandibular disorder } \\ \text { TMJ } & \text { temporomandibular joint }\end{array}$

\section{References}

1. Kiga, N. Histochemistry for studying structure and function of the articular disc of the human temporomandibular joint. Eur. J. Histochem. 2012, 56, e11. [CrossRef]

2. De Moraes, L.O.C.; Lodi, F.R.; Gomes, T.S.; Marques, S.R.; Oshima, C.T.F.; Lancellotti, C.L.P.; Rodríguez-Vázquez, J.F.; MéridaVelasco, J.R.; Alonso, L.G. Immunohistochemical expression of types I and III collagen antibodies in the temporomandibular joint disc of human foetuses. Eur. J. Histochem. 2011, 55, 129-132. [CrossRef] [PubMed]

3. Fazaeli, S.; Mirahmadi, F.; Everts, V.; Smit, T.H.; Koolstra, J.H.; Ghazanfari, S. Alteration of structural and mechanical properties of the temporomandibular joint disc following elastase digestion. J. Biomed. Mater. Res. Part B Appl. Biomater. 2020, 108, 3228-3240. [CrossRef] [PubMed]

4. Nell, A.; Niebauer, G.; Sperr, W.; Firbas, W. Special variations of the lateral ligament the human TMJ. Clin. Anat. 1994, 7, 267-270. [CrossRef] 
5. Miernik, M.; Więckiewicz, W. The basic conservative treatment of temporomandibular joint anterior disc displacement without reduction-Review. In Advances in Clinical and Experimental Medicine; Wroclaw University of Medicine: Wrocław, Poland, 2015; Volume 24, pp. 731-735.

6. Valladares-Neto, J.; Cevidanes, L.H.; Rocha, W.C.; Almeida, G.D.A.; de Paiva, J.B.; Rino-Neto, J. TMJ response to mandibular ad-vancement surgery: An overview of risk factors. In Journal of Applied Oral Science; Bauru School of Dentistry, University of Sao Paulo: São Paulo, Brazil, 2014; Volume 22, pp. 2-14.

7. Matsubara, R.; Yanagi, Y.; Oki, K.; Hisatomi, M.; Santos, K.C.; Bamgbose, B.O.; Fujita, M.; Okada, S.; Minagi, S.; Asaumi, J. Assessment of MRI findings and clinical symptoms in patients with temporomandibular joint disorders. Dentomaxillofacial Radiol. 2018, 47, 20170412. [CrossRef] [PubMed]

8. Orhan, K.; Seki, U.; Rozylo-Kalinowska, I. Diagnostic accuracy of magnetic resonance imaging and clinical signs of temporomandibular joint disorders: A 10-year research update review. Oral Radiol. 2017, 33, 81-91. [CrossRef]

9. De Senna, B.R.; Marques, L.S.; França, J.P.; Ramos-Jorge, M.L.; Pereira, L.J. Condyle-disk-fossa position and relationship to clinical signs and symptoms of temporomandibular disorders in women. Oral Surg. Oral Med. Oral Pathol. Oral Radiol. Endodontol. 2009, 108, e117-e124. [CrossRef] [PubMed]

10. Litko-Rola, M.; Szkutnik, J.; Różyło-Kalinowska, I. The importance of multisection sagittal and coronal magnetic resonance imaging evaluation in the assessment of temporomandibular joint disc position. Clin. Oral Investig. 2021, 25, 159-168. [CrossRef]

11. Okeson, J.P. Joint Intracapsular Disorders: Diagnostic and Nonsurgical Management Considerations. Dent. Clin. N. Am. 2007, 51, 85-103. [CrossRef]

12. Ahn, S.-J.; Chang, M.-S.; Choi, J.-H.; Yang, I.-H.; An, J.-S.; Heo, M.-S. Relationships between temporomandibular joint disk displacements and condylar volume. Oral Surg. Oral Med. Oral Pathol. Oral Radiol. 2018, 125, 192-198. [CrossRef]

13. Kellenberger, C.J.; Bucheli, J.; Schroeder-Kohler, S.; Saurenmann, R.K.; Colombo, V.; Ettlin, D.A. Temporomandibular joint magnetic resonance imaging findings in adolescents with anterior disk displacement compared to those with juvenile idiopathic arthritis. J. Oral Rehabil. 2018, 46, 14-22. [CrossRef] [PubMed]

14. Galiano, A.; Wolford, L.; Gonçalves, J.; Gonçalves, D. Adolescent internal condylar resorption (AICR) of the temporomandibular joint can be successfully treated by disc repositioning and orthognathic surgery, part 2: Treatment outcomes. CRANIO 2017, 37, 111-120. [CrossRef] [PubMed]

15. Shaefer, J.R.; Riley, C.J.; Caruso, P.; Keith, D. Analysis of criteria for MRI diagnosis of TMJ disc displacement and arthralgia. Int. J. Dent. 2012, 1-8. [CrossRef] [PubMed]

16. National Center for Biotechnology Information. dbSNP: Short Genetic Variations. Available online: http://www.ncbi.nlm.nih. gov / projects/SNP (accessed on 23 December 2020).

17. Kaynak, M.; Nijman, F.; van Meurs, J.; Reijman, M.; Meuffels, D.E. Genetic Variants and Anterior Cruciate Ligament Rupture: A Systematic Review. In Sports Medicine; Springer International Publishing: Berlin/Heidelberg, Germany, 2017; Volume 47, pp. 1637-1650. Available online: https:/ / pubmed.ncbi.nlm.nih.gov/28102489/ (accessed on 29 November 2020).

18. Zou, Y.; Zwolanek, D.; Izu, Y.; Gandhy, S.; Schreiber, G.; Brockmann, K.; Devoto, M.; Tian, Z.; Hu, Y.; Veit, G.; et al. Recessive and dominant mutations in COL12A1 cause a novel EDS/myopathy overlap syndrome in humans and mice. Hum. Mol. Genet. 2014, 23, 2339-2352. [CrossRef] [PubMed]

19. Derwich, M.; Mitus-Kenig, M.; Pawlowska, E. Temporomandibular Joints' Morphology and Osteoarthritic Changes in Cone-Beam Computed Tomography Images in Patients with and without Reciprocal Clicking-A Case Control Study. Int. J. Environ. Res. Public Health 2020, 17, 3428. [CrossRef] [PubMed]

20. Rechia, B.C.D.N.; Michels, B.; Faturri, A.L.; Bertoli, F.M.D.P.; Scariot, R.; De Souza, J.F.; Küchler, E.C.; Brancher, J.A. Polymorphisms in COL2A1 gene in Adolescents with Temporomandibular Disorders. J. Clin. Pediatr. Dent. 2020, 44, 364-372. [CrossRef] [PubMed]

21. Szklarczyk, D.; Gable, A.L.; Lyon, D.; Junge, A.; Wyder, S.; Huerta-Cepas, J.; Simonovic, M.; Doncheva, N.T.; Morris, J.H.; Bork, P.; et al. STRING v11: Protein-protein association networks with increased coverage, supporting functional discovery in genome-wide experimental datasets. Nucleic Acids Res. 2019, 47, D607-D613. [CrossRef] [PubMed]

22. Ohrbach, R.; Dworkin, S.F. AAPT Diagnostic Criteria for Chronic Painful Temporomandibular Disorders. J. Pain 2019, 20, 1276-1292. [CrossRef]

23. Skeie, M.S.; Frid, P.; Mustafa, M.; Aßmus, J.; Rosén, A. DC/TMD Examiner Protocol: Longitudinal Evaluation on Interexaminer Reliability. Pain Res. Manag. 2018, 2018, 1-8. [CrossRef]

24. Pihut, M.; Gorecka, M.; Ceranowicz, P.; Więckiewicz, M. The Efficiency of Anterior Repositioning Splints in the Management of Pain Related to Temporomandibular Joint Disc Displacement with Reduction. Pain Res. Manag. 2018, 2018, 1-6. [CrossRef]

25. Dalewski, B.; Chruściel-Nogalska, M.; Frączak, B. Occlusal splint versus modified nociceptive trigeminal inhibition splint in bruxism therapy: A randomized, controlled trial using surface electromyography. Aust. Dent. J. 2015, 60, 445-454. [CrossRef]

26. Dalewski, B.; Kamińska, A.; Białkowska, K.; Jakubowska, A.; Sobolewska, E. Association of Estrogen Receptor 1 and Tumor Necrosis Factor $\alpha$ Polymorphisms with Temporomandibular Joint Anterior Disc Displacement without Reduction. Dis. Markers 2020, 2020, 1-9. [CrossRef] [PubMed]

27. Rajasekaran, S.; Tangavel, C.; Djuric, N.; Raveendran, M.; Soundararajan, D.C.R.; Nayagam, S.M.; Matchado, M.S.; Anand, K.S.S.V. Part 1: Profiling extra cellular matrix core proteome of human fetal nucleus pulposus in search for regenerative targets. Sci. Rep. 2020, 10, 1-15. [CrossRef] [PubMed] 
28. Wei, Y.; Tassava, R.A. Expression of type XII collagen by wound epithelial, mesenchymal, and ependymal cells during blastema formation in regenerating newt (Notophthalmusviridescens) tails. J. Morphol. 1996, 230, 177-186. [CrossRef]

29. Chiquet, M.; Birk, D.E.; Bönnemann, C.G.; Koch, M. Collagen XII: Protecting bone and muscle integrity by organizing collagen fibrils. Int. J. Biochem. Cell Biol. 2014, 53, 51-54. [CrossRef] [PubMed]

30. Hicks, D.; Farsani, G.T.; Laval, S.; Collins, J.; Sarkozy, A.; Martoni, E.; Shah, A.; Zou, Y.; Koch, M.; Bönnemann, C.G.; et al. Mutations in the collagen XII gene define a new form of extracellular matrix-related myopathy. Hum. Mol. Genet. 2013, 23, 2353-2363. [CrossRef]

31. Punetha, J.; Kesari, A.; Hoffman, E.P.; Gos, M.; Kamińska, A.; Kostera-Pruszczyk, A.; Hausmanowa-Petrusewicz, I.; Hu, Y.; Zou, Y.; Bönnemann, C.G.; et al. NovelCol12A1variant expands the clinical picture of congenital myopathies with extracellular matrix defects. Muscle Nerve 2017, 55, 277-281. [CrossRef]

32. Lories, R.J.; Luyten, F.P. Overview of Joint and Cartilage Biology. Genet. Bone Biol. Skelet. Dis. 2013, 209-225. [CrossRef]

33. Huang, B.; Pathria, M.; Tadros, A. Muscle-Tendon-Enthesis Unit. Semin. Musculoskelet. Radiol. 2018, 22, 263-274. [CrossRef]

34. Harada, Y.; Mifune, Y.; Inui, A.; Sakata, R.; Muto, T.; Takase, F.; Ueda, Y.; Kataoka, T.; Kokubu, T.; Kuroda, R.; et al. Rotator cuff repair using cell sheets derived from human rotator cuff in a rat model. J. Orthop. Res. 2017, 35, 289-296. [CrossRef]

35. September, A.V.; Posthumus, M.; Van Der Merwe, L.; Schwellnus, M.; Noakes, T.D.; Collins, M. The COL12A1 and COL14A1 genes and Achilles tendon injuries. Int. J. Sports Med. 2008, 29, 257-263. [CrossRef] [PubMed]

36. Araújo, D.; Antunes, H. A novel mutation in the COL12A1 gene. Gene 2021, 768, 145266. [CrossRef] [PubMed]

37. O'Connell, K.; Posthumus, M.; Collins, M. No association between COL3A1, COL6A1 or COL12A1 gene variants and range of motion. J. Sports Sci. 2012, 31, 181-187. [CrossRef] [PubMed]

38. Jezela-Stanek, A.; Walczak, A.; Łaźniewski, M.; Kosińska, J.; Stawiński, P.; Pienkowski, V.M.; Biernacka, A.; Rydzanicz, M.; Kostrzewa, G.; Krajewski, P.; et al. Novel COL12A1 variant as a cause of mild familial extracellular matrix-related myopathy. Clin. Genet. 2019, 95, 736-738. [CrossRef]

39. Posthumus, M.; September, A.V.; O'Cuinneagain, D.; Van Der Merwe, W.; Schwellnus, M.P.; Collins, M. The association between the COL12A1 gene and anterior cruciate ligament ruptures. Br. J. Sports Med. 2009, 44, 1160-1165. [CrossRef] [PubMed]

40. Ficek, K.; Stepien-Slodkowska, M.; Kaczmarczyk, M.; Maciejewska-Karlowska, A.; Sawczuk, M.; Cholewinski, J.; Leonska-Duniec, A.; Zarebska, A.; Cieszczyk, P.; Zmijewski, P. Does the A9285G polymorphism in collagen type XII alpha1 gene associate with the risk of anterior cruciate ligament ruptures? Balk. J. Med. Genet. 2014, 17, 41-46.

41. O'Connell, K.; Knight, H.; Ficek, K.; Leonska-Duniec, A.; Maciejewska-Karlowska, A.; Sawczuk, M.; Stepien-Slodkowska, M.; O'Cuinneagain, D.; Van Der Merwe, W.; Posthumus, M.; et al. Interactions between collagen gene variants and risk of anterior cruciate ligament rupture. Eur. J. Sport Sci. 2014, 15, 341-350. [CrossRef] [PubMed]

42. The UniProt Consortium Ongoing and Future Developments at the Universal Protein Resource. Nucleic Acids Res. 2011, 39, D214-D219. [CrossRef]

43. Kania, A.M.; Reichenberger, E.; Baur, S.T.; Karimbux, N.Y.; Taylor, R.W.; Olsen, B.R.; Nishimura, I. Structural Variation of Type XII Collagen at Its Carboxyl-terminal NC1 Domain Generated by Tissue-specific Alternative Splicing. J. Biol. Chem. 1999, 274, 22053-22059. [CrossRef]

44. Bell, R.D.; Shultz, S.J.; Wideman, L.; Henrich, V.C. Collagen Gene Variants Previously Associated With Anterior Cruciate Ligament Injury Risk Are Also Associated With Joint Laxity. Sports Health A Multidiscip. Approach 2012, 4, 312-318. [CrossRef]

45. Novaretti, J.V.; Astur, D.C.; Casadio, D.; Nicolini, A.P.; Pochini, A.D.C.; Andreoli, C.V.; Ejnisman, B.; Cohen, M. Higher Gene Expression of Healing Factors in Anterior Cruciate Ligament Remnant in Acute Anterior Cruciate Ligament Tear. Am. J. Sports Med. 2018, 46, 1583-1591. [CrossRef] [PubMed]

46. Izu, Y.; Adams, S.M.; Connizzo, B.K.; Beason, D.P.; Soslowsky, L.J.; Koch, M.; Birk, D.E. Collagen XII mediated cellular and extracellular mechanisms regulate establishment of tendon structure and function. Matrix Biol. 2021, 95, 52-67. [CrossRef] [PubMed] 